\title{
Acute phase markers in obese children and adolescents with metabolic disorders
}

\author{
Idalia Cura-Esquivel, M.D. ${ }^{a}$, Paula Cordero-Pérez, M.D. ${ }^{b}$, Liliana Torres-González, M.D. ${ }^{b}$ and \\ Linda E. Muñoz-Espinosa, M.D. ${ }^{b}$
}

\begin{abstract}
Introduction. Obesity is a worldwide public health problem and the most common non-communicable chronic disease. It is associated with an increase in inflammatory acute phase proteins and proinflammatory cytokines.

Objective. To assess the levels of acute phase proteins in obese children and adolescents with hepatic steatosis and metabolic syndrome.

Methodology. Forty-five children with a body mass index $\geq 95^{\text {th }}$ percentile aged 5.0-15.5 years were included. The following acute phase reactants were determined: C-reactive protein, haptoglobin, alpha-2-macroglobulin, and apolipoprotein A-1; besides, an ultrasound was done to assess hepatic steatosis. Results. C-reactive protein levels increased in all patients. Patients with metabolic syndrome also had high levels of apolipoprotein A-1 and haptoglobin. Patients with hepatic steatosis had a significant increase in alpha-2-macroglobulin in addition to high C-reactive protein.

Key words: obesity, C-reactive protein, haptoglobins, alpha-2macroglobulins, apolipoprotein A-1.
\end{abstract}

http:/ / dx.doi.org/10.5546/ aap.2018.eng.275

To cite: Cura-Esquivel I, Cordero-Pérez P, Torres-González L, MuñozEspinosa LE. Acute phase markers in obese children and adolescents with metabolic disorders. Arch Argent Pediatr 2018;116(4):275-279.

a. Department of Pediatrics, Hospital Universitario "Dr. José E. González."

b. Unit of Liver Disease, Hospital Universitario "Dr. José E. González." Universidad Autónoma de Nuevo León, Mexico.

E-mail addres:

Cura-Esquivel, Idalia M.D.: idaliaaracely2008@hotmail.com

Funding: This study was financially supported by the Support Program for Scientific and Technological Research (Programa de Apoyo a la Investigación Científica y Tecnológica, PAICYT) of Universidad Autónoma de Nuevo León.

Conflict of interest: None.

Received: 6-9-2017

Accepted: 12-7-2017

\section{INTRODUCTION}

Obesity is defined as an excessive body fat accumulation caused by a high-energy intake plus low energy expenditure. It is the most frequent non-communicable chronic disease among children and adults. ${ }^{1,2}$ In Mexico, the prevalence of overweight and obesity among schoolchildren is $33.2 \%$, according to the latest National Survey on Nutrition and Health (ENSANUT 2016). ${ }^{3}$ Obesity is regulated by a series of adipokines, including leptin, adiponectin, haptoglobin, and serum amyloid. These mediators produced in adipose tissue induce a low-grade systemic inflammation and this process is a mechanism relating obesity to a range of associated pathologies. ${ }^{4}$ Multiple studies have demonstrated the association between body mass index (BMI) and visceral obesity and their complications, such as metabolic syndrome (MS), with high levels of non-specific inflammation mediators, including C-reactive protein (CRP), inflammatory acute phase proteins and other proinflammatory cytokines. ${ }^{4,5}$

The objective of this study was to assess acute phase proteins in obese children and adolescents with hepatic steatosis and MS.

\section{POPULATION AND METHODS}

Observational, longitudinal, analytical and prospective study conducted between January 2009 and December 2013. Patients aged 5-15.5 years, seen at the Department of Pediatrics of Hospital Universitario “Dr. José Eleuterio González" of Universidad Autónoma de Nuevo León (UANL), who had a BMI $\geq 95^{\text {th }}$ percentile according to the Centers for Disease Control and Prevention (CDC) charts for age and sex were included. BMI was estimated based on the weight $(\mathrm{kg}) /$ height $\left(\mathrm{m}^{2}\right)$ formula. The clinical and anthropometric assessment included weight, height, and waist circumference (WC) measurements; an abdominal ultrasound was also done to determine the presence of hepatic steatosis. The grade of hepatic steatosis was classified from 0 (without steatosis) to 3 (severe steatosis). The presence of MS was assessed based on the criteria of the International Diabetes 
Federation (IDF), which establishes the presence of central obesity plus two or more clinical results: triglycerides $\geq 150 \mathrm{mg} / \mathrm{dL}$, high-density lipoproteins (HDL) $<40 \mathrm{mg} / \mathrm{dL}$ for men and $<50 \mathrm{mg} / \mathrm{dL}$ for women, hypertension (blood pressure $[\mathrm{BP}]>97^{\text {th }}$ percentile), oral glucose tolerance test $>100$ or type 2 diabetes mellitus (DM), waist circumference $\geq 90^{\text {th }}$ percentile. $^{6}$ Patients previously diagnosed with acute or chronic liver disease, endocrinological, genetic or kidney disorders, or those who refused to participate in the study were excluded.

For the determination of acute phase proteins and liver function tests, $8 \mathrm{~mL}$ of blood $(5 \mathrm{~mL}$ for serum and $3 \mathrm{~mL}$ for blood with EDTA) were collected. CRP, haptoglobin, alpha-2macroglobulin $\left(\alpha_{2} \mathrm{M}\right)$, and apolipoprotein A-1 (APO A-1) were measured in serum.

The descriptive analysis of continuous outcome measures was expressed as mean \pm standard deviation (SD). Categorical outcome measures were indicated as frequency and proportions. The relationship between biochemical tests and acute inflammatory markers was analyzed using Spearman's correlation for non-parametric data and Pearson's correlation for parametric data. The SPSS statistical software, version 16.0, was used to this end. A value of $p<$ 0.05 was considered statistically significant.

\section{Ethical aspects}

This study was approved by the Ethics Committee of our institution (PE08-008). All patients gave their assent, and their parents signed an informed consent form.

\section{RESULTS}

A total of 45 patients were included; 19 (46\%) were girls and $26(57.8 \%)$, boys. The mean age of the group was $11 \pm 2.2$ years (5-15 years). The BMI was $27.07 \pm 5.9 \mathrm{~kg} / \mathrm{m}^{2}$ of body surface area (BSA) $\left(22.4-37.8 \mathrm{~kg} / \mathrm{m}^{2}\right.$ of BSA). All patients were diagnosed with obesity based on their BMI percentile. The $\mathrm{WC}$ was $90 \pm 17 \mathrm{~cm}$ with a waist/ hip ratio of $0.85 \pm 0.18 \mathrm{~cm}$.

\section{Acute phase reactants}

Only CRP $(4.65 \pm 5.5 \mathrm{mg} / \mathrm{dL}$ versus $0.25 \pm 0.33 \mathrm{mg} / \mathrm{dL}, p<0.001)$ showed significantly high levels in all patients. When assessing levels by sex, girls had higher levels than boys ( $5.72 \pm 7.5$ versus $3.34 \pm 3.77 \mathrm{mg} / \mathrm{dL}, p=0.02$ ), contrary to what was observed with $\alpha_{2} \mathrm{M}$, which was higher in boys $(3.05 \pm 0.60$ versus $2.74 \pm 0.43 \mathrm{mg} / \mathrm{dL}$, $p<0.05)$. When correlating anthropometric and biochemical parameters and acute phase proteins, a positive correlation was observed between CRP and BMI $(\mathrm{r}=0.34, p<0.01), \mathrm{CRP}$ and $\mathrm{WC}(\mathrm{r}=0.76$, $p<0.001)$, CRP and gamma-glutamyl transferase

TABLE 1. Correlation among anthropometric and biochemical outcome measures

\begin{tabular}{|c|c|c|c|c|c|c|c|c|}
\hline \multicolumn{9}{|l|}{$\mathrm{N}=45$} \\
\hline Outcome measure & BMI & Triglycerides & TC & ALT & AST & GGT & Glucose & CRP \\
\hline Triglycerides & $0.08 / 0.57$ & & & & & & & \\
\hline $\mathrm{TC}$ & $-0.13 / 0.37$ & $0.58 / 0.70$ & & & & & & \\
\hline ALT & $-0.09 / 0.95$ & $-0.23 / 0.87$ & $0.98 / 0.52$ & & & & & \\
\hline AST & $-0.22 / 0.14$ & $-0.16 / 0.29$ & $0.99 / 0.51$ & $0.68 / 0.01$ & & & & \\
\hline $\mathrm{AP}$ & $-0.15 / 0.31$ & $0.61 / 0.69$ & $0.14 / 0.33$ & $0.24 / 0.10$ & $0.11 / 0.45$ & & & \\
\hline GGT & $0.78 / 0.61$ & $0.98 / 0.52$ & $0.82 / 0.59$ & $0.51 / 0.01$ & $0.44 / 0.02$ & & & \\
\hline Glucose & $0.28 / 0.05$ & $0.45 / 0.77$ & $0.29 / 0.04$ & $0.11 / 0.23$ & $0.21 / 0.15$ & $0.21 / 0.15$ & & \\
\hline CRP & $0.34 / 0.01$ & $0.53 / 0.72$ & $-0.45 / 0.76$ & $0.06 / 0.69$ & $0.38 / 0.80$ & $0.38 / 0.04$ & $0.13 / 0.38$ & \\
\hline$\alpha 2 \mathrm{M}$ & $0.06 / 0.97$ & $0.06 / 0.68$ & $0.29 / 0.05$ & $-0.02 / 0.87$ & $-0.12 / 0.40$ & $0.04 / 0.97$ & $0.09 / 0.55$ & $-0.29 / 0.04$ \\
\hline APO A-1 & $0.22 / 0.13$ & $-0.20 / 0.05$ & $0.20 / 0.17$ & $0.13 / 0.39$ & $0.10 / 0.48$ & $0.08 / 0.58$ & $0.30 / 0.03$ & $0.32 / 0.03$ \\
\hline Haptoglobin & $-0.20 / 0.18$ & $0.02 / 0.89$ & $0.56 / 0.01$ & $0.25 / 0.09$ & $0.34 / 0.02$ & $0.20 / 0.16$ & $-0.09 / 0.52$ & $0.12 / 0.40$ \\
\hline
\end{tabular}

BMI: body mass index; TC: total cholesterol; ALT: alanine aminotransferase; AST: aspartate aminotransferase; AP: alkalinephosphatase; GGT: gamma-glutamyl transferase; CRP: C-reactive protein; $\alpha 2 \mathrm{M}$ : alpha-2-macroglobulin; APO A-1: apolipoprotein A-1. 
(GGT) $(\mathrm{r}=0.38, p<0.04), \mathrm{CRP}$ and $\alpha_{2} \mathrm{M}(\mathrm{r}=0.29$, $p<0.04)$, and CRP and APO A-1 ( $\mathrm{r}=0.32, p<0.03)$ (Table 1).

\section{Obesity and metabolic syndrome}

Based on the IDF's criteria, $24(53 \%)$ patients, 8 girls and 16 boys, were diagnosed with MS. CRP levels were higher in patients with MS $(4.05 \pm 5.1$ versus $2.15 \pm 4.7 \mathrm{mg} / \mathrm{dL}, p<0.001)$. A progressive rise was observed as the number of MS components increased. The mean CRP level among patients with $0,1,2,3$, and 4 components of MS was 2.6, 2.52, 2.86, 6.04, and $16.5 \mathrm{mg} / \mathrm{dL}$, respectively. APO A-1 levels ( $1.14 \pm 0.33$ versus $0.50 \pm 0.56 \mathrm{mg} / \mathrm{dL}, p<0.001)$ and haptoglobin levels $(1.46 \pm 0.26$ versus $1.30 \pm 0.27 \mathrm{mg} / \mathrm{dL}$, $p<0.001$ ) were higher and statistically significant, whereas $\alpha_{2} \mathrm{M}$ was slightly higher in the MS group, without a significant difference $(p=0.08)$ (Figure 1).

\section{Obesity and hepatic steatosis}

Hepatic steatosis was diagnosed by ultrasound in $21(46.6 \%)$ patients; 13 had mild steatosis; 6 , moderate steatosis; and 2, severe steatosis. CRP levels ( $5.2 \pm 6.6 \mathrm{mg} / \mathrm{dL}$ versus $1.9 \pm 3.6 \mathrm{mg} /$ $\mathrm{dL}, p<0.001)$ and $\alpha_{2} \mathrm{M}$ levels $(3.12 \pm 0.68$ versus $2.75 \pm 0.35 \mathrm{mg} / \mathrm{dL}, p=0.03$ ) were significantly higher among patients with hepatic steatosis, whereas haptoglobin levels (1.44 \pm 0.27 versus $1.38 \pm 0.23 \mathrm{mg} / \mathrm{dL}, p=0.82)$ and APO A-1 levels $(1.15 \pm 0.29$ versus $1.05 \pm 0.537 \mathrm{mg} / \mathrm{dL}, p=0.09)$ did not show a statistically significant difference (Figure 2).

\section{DISCUSSION}

CRP and other acute phase reactants have been involved in the diagnosis of inflammation described in obese patients. $\mathrm{A}_{2} \mathrm{M}$ is a liver protein that, in patients with nonalcoholic fatty liver, has been associated with the fibrogenesis process. APO A-1, which is also synthesized by the liver, is the main component of HDL, plays a role in cholesterol homeostasis, and decreases as liver fibrosis and cirrhosis progress, whereas haptoglobin, also synthesized by the liver, reduces during fibrogenesis. ${ }^{7,8}$ Our results evidence a positive correlation between a high BMI and acute phase reactants.

A liver ultrasound is a safe, well-tolerated, cost-effective, easily-available, and widely accepted imaging test to diagnose fatty liver. Recent studies have demonstrated that it is sensitive enough to detect an amount of steatosis as low as $10-20 \% .{ }^{9}$ Hepatic steatosis was diagnosed by ultrasound in 21 patients and was,

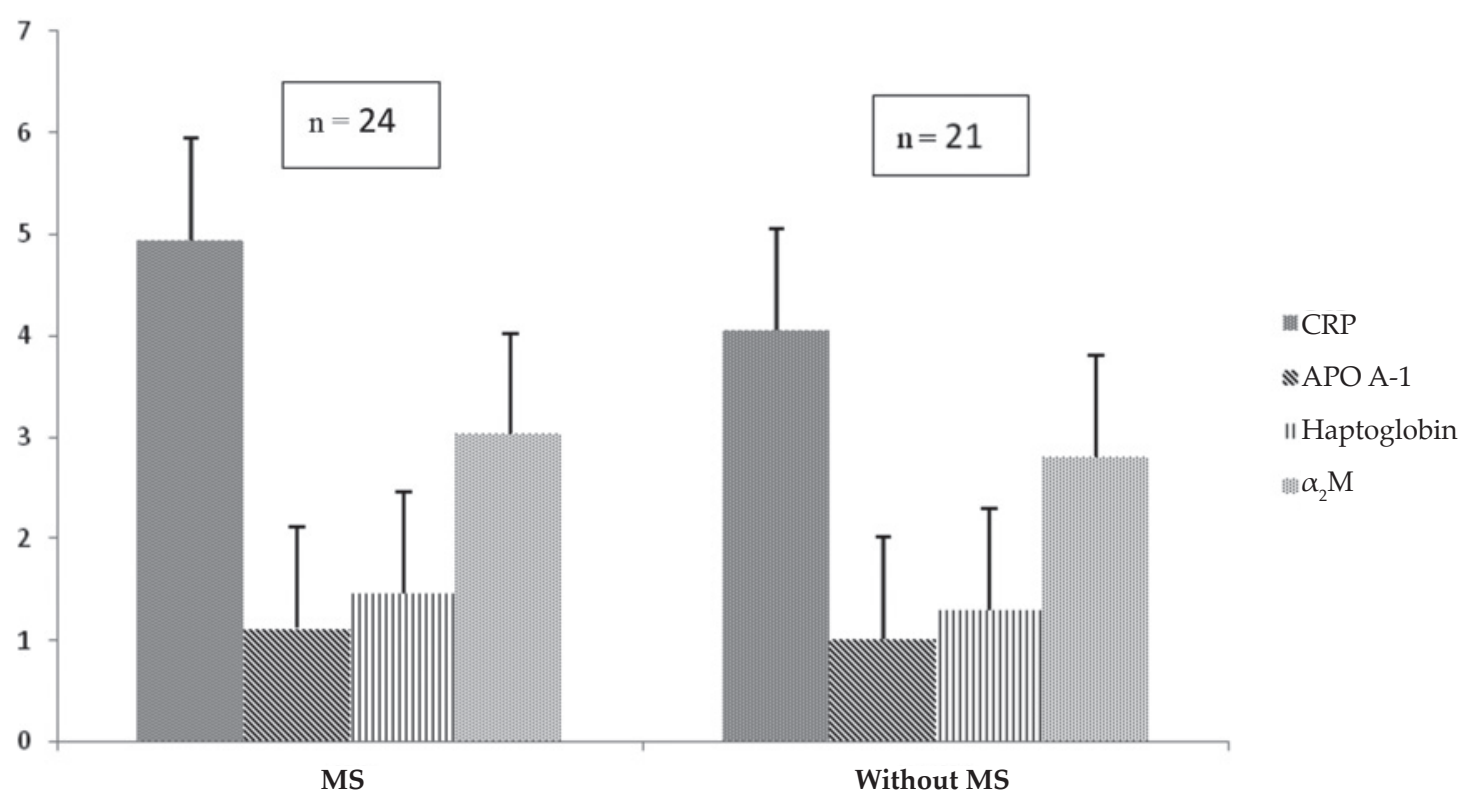

MS: metabolic syndrome; CRP: C-reactive protein; APO A-1: apolipoprotein A-1; $\alpha_{2}$ M: alpha-2-macroglobulin. 
in most cases, mild, with significantly higher CRP and $\alpha_{2} \mathrm{M}$ levels than in patients without steatosis. Our findings are consistent with what has been observed in previous studies, thus suggesting a low-grade inflammation in the liver.

Some authors, such as Bogdanski et al. and Vallianou et al., assessed acute phase reactants (CRP, haptoglobin, $\alpha_{2} \mathrm{M}$ ) in patients with MS and found that these proteins were significantly high in these patients. They suggested that both CRP and haptoglobin may serve as markers of MS severity. 7,10 That study on CRP, showed that APO A-1 and haptoglobin were significantly high in patients with MS, also in association with a chronic inflammation concurrent with other pathologies developed with steatosis and fibrosis, as observed in hepatitis C. ${ }^{11}$

In our study, CRP and APO A- 1 were associated with obesity and MS, whereas BMI and CRP were strongly associated with the severity of steatosis.

The weaknesses of our study were, above all, the number of patients and the wide age range, which restricted our analysis. Pubertal stage was not considered either, which might have shown differences in findings, especially if the effect of estrogens on transcriptional control, clearance, and regulation of some of the liver-produced proteins (cytokines) -including CRP- had been considered, which could have influenced the outcomes.
To sum up, all patients showed an increase in the CRP level, regardless of BMI and metabolic status. Patients with MS also showed high APO A-1 and haptoglobin levels, whereas patients with hepatic steatosis also had a significant increase of $\alpha_{2} \mathrm{M}$.

\section{REFERENCES}

1. Güngör NK. Overweight and obesity in children and adolescents. J Clin Res Pediatr Endocrinol 2014; 6(3):129-43.

2. Han JC, Lawlor DA, Kimm SY. Childhood obesity. Lancet 2010; 375(9727):1737-48.

3. Gutiérrez JP, Rivera-Dommarco J, Shamah-Levy T, et al. Encuesta Nacional de Salud y Nutrición 2016. Resultados Nacionales. Cuernavaca: Instituto Nacional de Salud Pública; 2016.

4. Singer K, Lumeng CN. The initiation of metabolic inflammation in childhood obesity. J Clin Invest 2017; 127(1):65-73.

5. Dedoussis GV, Kapiri A, Samara A, et al. Expression of inflammatory molecules and associations with BMI in children. Eur J Clin Invest 2010; 40(5):388-92.

6. Alberti KG, Zimmet P, Shaw J, et al. The metabolic syndrome--a new worldwide definition. Lancet 2005; 366(9491):1059-62.

7. Vallianou NG, Evangelopoulos AA, Panagiotakos DB, Georgiou AT, et al. Associations of acute-phase reactants with metabolic syndrome in middle-aged overweight or obese people. Med Sci Monit 2010;16(2):CR56-60.

8. Zimmermann E, Anty R, Tordjman J, et al. C-reactive protein levels in relation to various features of nonalcoholic fatty liver disease among obese patients. J Hepatol 2011; 55(3):660-5.

9. Bril F, Ortiz-Lopez C, Lomonaco R, et al. Clinical value of liver ultrasound for the diagnosis of nonalcoholic fatty

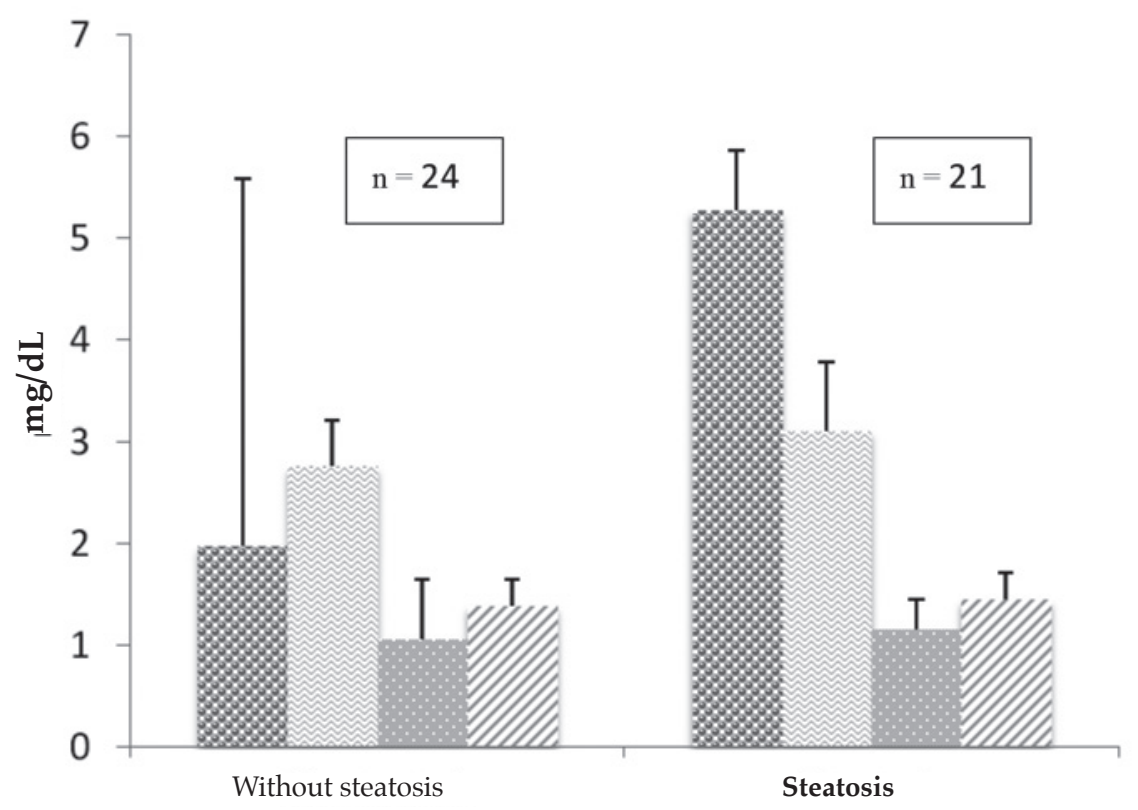

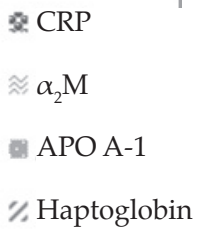

Steatosis

CRP: C-reactive protein; APO A-1: apolipoprotein A-1; $\alpha_{2}$ M: alpha-2-macroglobulin. 
liver disease in overweight and obese patients. Liver Int 2015; 35(9):2139-46.

10. Bogdański P,Chyrek R, Pupek-MusialikD, etal.Evaluation of selected acute phase proteins in patients with metabolic syndrome. Pol Mer kur Lekarski 2006; 21(121):12-4

11. ParkSH, Kim CH, Kim DJ, etal. Diagnostic value of multiple biomarker panel for prediction of significant fibrosis in chronic hepatitis C. ClinBiochem2011;44(17-18):1396-9.

\title{
Characterization of drug poisoning among adolescents seen at the municipal hospital of Bahía Blanca, Province of Buenos Aires, Argentina
}

\author{
Ignacio Buffone, M.D. ${ }^{a}$, Mabel Dejter, M.D. ${ }^{a}$, Eliana Fortunatti, M.D. ${ }^{a}$, Florencia García Elliot, M.D. ${ }^{a}$, \\ Camila Irazabal, M.D. ${ }^{a}$, Rubén Marlia, M.D. ${ }^{a}$, Daiana Mujica, M.D. ${ }^{a}$, Marianela Parrou, M.D. ${ }^{a}$, \\ Mariana Romano, M.D. ${ }^{a}$, Gina Speciale, M.D. ${ }^{a}$ and Agostina Werneke, M.D. ${ }^{a}$
}

\begin{abstract}
Introduction. Drug poisoning among children is a frequent reason for visits to the emergency department; among adolescents, it is intentional.

Objective. To describe the characteristics of drug poisoning among adolescents admitted to the municipal hospital of Bahía Blanca.

Material and method. Descriptive study based on the review of medical records of patients aged 10-19 years seen for drug poisoning between 2012 and 2016. The following outcome measures were analyzed: age, sex, drug used, cause, clinical manifestations, and length of stay in days.

Results. Data from 72 patients were collected. Their mean age was 16 years, and the female:male ratio was 2.5:1. Anxiolytic poisoning $(30 \%)$ predominated, followed by polydrug use $(25 \%)$. Ninety-five percent of patients showed a suicidal intention; of these, $55 \%$ had a history of suicide attempt.

Conclusion. Drug poisoning was observed predominantly among girls; it is worth noting the high percentage of youth who had a history of suicide attempt.

Key words: adolescent, drug poisoning.
\end{abstract}

http: / / dx.doi.org/10.5546/ aap.2018.eng.279

To cite: Buffone I, Dejter M, Fortunatti E, et al. Characterization of drug poisoning among adolescents seen at the municipal hospital of Bahía Blanca, Province of Buenos Aires, Argentina. Arch Argent Pediatr 2018;116(4):279-282.

a. Department of Clinical Pediatrics, Hospital Municipal de Agudos "Dr. Leónidas Lucero," Bahía Blanca, Province of Buenos Aires.

E-mail address:

Ignacio Buffone, M.D.: nacho_b89@hotmail.com

Funding: None.

Conflict of interest: None.

Received: 7-16-2017

Accepted: 12-21-2017

\section{INTRODUCTION}

In recent years, drug poisoning among adolescents has become a serious public health problem, especially in the field of pediatrics. It is the cause of up to $10 \%$ of all admissions to the intensive care unit, and the mortality rate is highly variable depending on the different health care scenarios. ${ }^{1}$

The substances involved vary greatly; antidepressants, anxiolytics, and non-steroidal anti-inflammatory drugs are the most common drug groups seen in these cases. ${ }^{2}$ Suicide attempt is the main cause of drug poisoning and one of the most concerning problems among individuals in this age group. ${ }^{3}$

At present, this is not an isolated phenomenon, but quite an everyday thing, especially among adolescents who are more prone to risk behaviors, given the changes typical of this development stage and the effect of an increasingly weakening of their social ties.

Considering the major role of this type of visits at the emergency department and because of the need to collect data to supplement local information, we decided to carry out a research study to describe the characteristics of the epidemiological patterns of drug poisoning among adolescents aged 10-19 years admitted to the emergency department of Hospital Municipal de Agudos “Dr. Leónidas Lucero" (HMALL).

\section{METHODOLOGY}

Descriptive, retrospective study based on the data collected from reviewing the medical records of patients aged 10-19 years seen at the emergency department of HMALL due to drug poisoning 